\title{
Therapeutic enhancement of a cytotoxic agent using Photochemical internalisation in 3D compressed collagen constructs of ovarian cancer
}

\author{
Layla Mohammad Hadi*, Elnaz Yaghini, Katerina Stamati, Marilena Loizidou*, Alexander J. MacRobert \\ Division of Surgery \& Interventional Science, University College London, London, UK \\ *Corresponding authors: layla.hadi.13@ucl.ac.uk; $\underline{\text { m.loizidou@ucl.ac.uk }}$
}

\begin{abstract}
Photochemical internalisation $(\mathrm{PCl})$ is a method for enhancing delivery of drugs to their intracellular target sites of action. In this study we investigated the efficacy of PCl using a porphyrin photosensitiser and a cytotoxic agent on spheroid and non-spheroid compressed collagen 3D constructs of ovarian cancer versus conventional 2D culture. The therapeutic responses of two human carcinoma cell lines (SKOV3 and HEY) were compared using a range of assays including optical imaging. The treatment was shown to be effective in non-spheroid constructs of both cell lines causing a significant and synergistic reduction in cell viability measured at 48 or 96 hours post-illumination. In the larger spheroid constructs, PCl was still effective but required higher saporin and photosensitiser doses. Moreover, in contrast to the 2D and non-spheroid experiments, where comparable efficacy was found for the two cell lines, HEY spheroid constructs were found to be more susceptible to PCl and a lower dose of saporin could be used. $\mathrm{PCl}$ treatment was observed to induce death principally by apoptosis in the 3D constructs compared to the mostly necrotic cell death caused by PDT. At low oxygen levels (1\%) both PDT and PCI were significantly less effective in the constructs.
\end{abstract}

Key words: Ovarian cancer, Photochemical internalisation, Photodynamic therapy, 3D compressed collagen construct, Spheroid

\section{Introduction}

Ovarian cancer is one of the commonest causes of death from cancer in women. It is often diagnosed at an advanced stage and displays resistance towards the therapeutic drugs, which has led to the search for new and more effective treatments of this disease $(1,2)$. Photochemical Internalisation $(\mathrm{PCl})$ is derived from Photodynamic therapy (PDT) and is designed to enhance cytosolic delivery of therapeutic macromolecules and certain smaller molecules that are prone to endolysosomal entrapment and degradation. Its efficacy as a drug delivery technique has been demonstrated on conventional in vitro monolayer models and in vivo models including drug-resistant cancers (3-6). In the present study we have extended our investigations on PCI to three-dimensional (3D) constructs of ovarian cancer, which is becoming a widely used approach for assessing drug delivery systems (7). 
PCI utilises an amphiphilic photosensitiser (PS) that localises primarily in the membranes of endolysosomal vesicles, whereas the bioactive agent resides in the inner aqueous compartment. Photoactivation using low power visible light at a pre-selected time after administration of the agent damages the photosensitised endolysosomal membranes via reactive oxygen species (ROS) thereby releasing the entrapped agent into the cytosol so that they can reach their intended intracellular target (8-10). The potential of $\mathrm{PCI}$ in treating head and neck cancer has been shown in a recent clinical trial study using bleomycin as the chemotherapeutic (11). The commonly used PCl photosensitiser, meso-tetraphenyl porphine disulfonate (TPPS 2 ), has two sulfonate groups substituted on adjacent phenyl rings of the porphyrin macrocycle which reside at the aqueous-lipid interface with the hydrophobic portion of the macrocycle inserted into the lipid bilayer (12-14). Conjugation of a hydrophobic porphyrin or chlorin with a cell penetrating peptide has also been shown to provide suitable photosensitising properties for $\mathrm{PCl}(9,10,14-16)$. An interesting feature of this photosensitiser is that it is not a substrate for efflux via ABCG2 transporters which mediate cellular multidrug resistance $(3,6,17,18)$.

A widely used cytotoxin for experimental PCl is saporin which is a Type 1 ribosome-inactivating protein (RIP) obtained from a plant as a toxic enzyme (19). RIPs are involved in the removal of the A4324 adenine residue in the rat ribosome resulting in interference in the interaction between the ribosome and elongation factor 2, causing irreversible damage to ribosomes hence inhibiting protein synthesis (20). Since saporin is susceptible to both endolysosomal sequestration and degradation, it is a suitable model cytotoxic agent for $\operatorname{PCl}(5,21)$.

The development of three-dimensional (3D) cancer models has provided a means of recapitulating fundamental aspects of a solid cancer tissue, including tumour-stromal cell interactions $(22,23)$. The advantages of using such models over simple two-dimensional (2D) cell culture include the enhancement of the expression of differentiated functions, improvement of cell or tissue organisation, anti-apoptotic signalling, multicellular resistance as well as expression of hypoxic conditions and limited drug penetration. Their cellular and stromal characteristics can be reproducibly manipulated to provide a more representative platform for assessing the therapeutic response as an alternative to animal model testing (24-29). The large volume of extra fluid normally residing within fully hydrated 3D hydrogel models greatly reduces their density and their ability to mimic the dense cancer/stromal environment found in vivo $(30,31)$. In this study, we employed compressed type 1 collagen hydrogels, which have a much higher density of collagen (10\% wt/wt) compared to standard hydrogels, and therefore represent a more biomimetic construct. The compression of the hydrogels (via plastic compression) is achieved by removal of most of the excess interstitial fluid thus increasing cell-collagen density (32), as depicted in Figure S1. This results in changes in the cell growth rate and morphologies and can enable a hypoxic core to be created owing to the slower rate of oxygen diffusion through the denser collagen thus providing a better imitation of the in vivo scenario $(30,33,34)$. A 
commercially available kit can now be used for fabrication of plastic compressed 3D collagen gels and was used in this study.

The utility of 3D models for testing photosensitisers for PDT has been investigated in our laboratory and others $(27,35,36)$ and recently reviewed $(31)$. In this study we explore the efficacy of PCI in compressed 3D cancer constructs in two human ovarian cancer cell lines, HEY and SKOV3, including longer-term cell seeding and culturing to generate multicellular spheroids. These cell lines form papillary cystadenocarcinomas and clear cell adenocarcinomas, respectively.

\section{Methods and Materials}

\section{$2.1 \quad$ Cell culture}

Human ovarian carcinoma cell lines (SKOV3 and HEY were obtained from American Type Culture Collection, ATCC). Cells were cultured in DMEM/F12 medium (Sigma Aldrich), supplemented with 10\% FBS (Thermo Fisher Scientific) and $1 \%$ penicillin $(5000$ units $/ \mathrm{ml})$ and streptomycin $(5000 \mu \mathrm{g} / \mathrm{ml})$ (Thermo Fisher Scientific).

\subsection{Manufacture of 3D cancer constructs}

The 3D in vitro cancer constructs were manufactured following the protocol from RAFT 3D culture systems (Lonza, Slough, UK) $(37,38)$. The hydrogels were prepared from a mixture containing 10\% 10x MEM (used as colour/pH indicator), 80\% Rat Tail Collagen Type I (First Link UK Ltd. Custom Bio-Reagents) before undergoing neutralisation using neutralising solution made from 1.65 M NaOH and 840 mM HEPES buffer solution (Thermo Fisher Scientific). The cells were seeded into the collagen at densities of either 75,000 cells for early, non-spheroid constructs or 50,000 cells for larger spheroid constructs at overall (cells and collagen mix) volumes of $240 \mu$ l per well in a 96 well plate. The constructs were incubated at $37^{\circ} \mathrm{C}$ for 15 minutes to set before being subjected to plastic compression using absorbers (Lonza), at room temperature for a further 15 minutes. After the removal of the absorbers, fresh medium was added, and cells returned to the incubator.

\subsection{Cell seeding and imaging of spheroid formation}

Experiments were performed firstly on non-spheroid constructs, consisting mostly of isolated single cells that were subjected to treatment 1 day after cell seeding and compression. Secondly, we investigated the response of larger spheroids, consisting of multicellular aggregates that grew over a period of 7 days prior to treatment. Cell morphology and spheroid formation at different time points (days 3,5 and 7) after the initial seeding and compression were investigated using fluorescently labelled Phalloidin to visualise filamentous actin, and the Hoechst 33258 dye to observe the cell nuclei. The constructs were fixed with Formalin (10\%) and washed with PBS. They were then permeabilised with $1 \% \mathrm{BSA}$ and $0.3 \%$ Triton $\mathrm{X}$ solution and stained with Phalloidin (2.5\% in BSA /Triton-X solution) 
for 90 minutes before washing with PBS (3x) and further staining with Hoechst $33258(\lambda \mathrm{Ex} / \mathrm{Em} 352 / 461 \mathrm{~nm}), 2 \mu \mathrm{g} / \mathrm{ml}$ in PBS for 10 minutes. Alexa Fluor 488 labelled Phalloidin ( $\lambda_{\mathrm{Ex} / \mathrm{Em}} 495 / 518 \mathrm{~nm}$, Molecular Probes, Life Technologies) and Hoechst 33258 ( $\lambda$ Ex/Em 352/461 nm, Sigma-Aldrich) were imaged using an EVOS fluorescence inverted microscope (EVOS FL color, Life Technologies). The cellular aggregate sizes were measured using image analysis by delineating the boundary and the area was computed by the software. Approximately 20-30 aggregates were measured per construct. The same imaging technique using Phalloidin/ Hoechst 33258 was used in subsequent therapeutic studies of spheroids. Image analysis of the fluorescence images was carried out using the open source ImageJ software (NIH, US).

\subsection{In vitro PDT/PCI phototoxicity studies in 2D monolayer model and 3D cancer constructs}

HEY and SKOV3 cells were seeded at a density of 5000 cells/well (2D models), 75,000 cells/well (3D non-spheroid constructs) and 50,000 cells/well (3D spheroid constructs) in 96 well plates for 24 hours. Concentrated stock solutions of the photosensitiser, TPPS $2 \mathrm{a}$ (Frontier Scientific Inc.), were prepared in dimethyl sulfoxide (DMSO). Mesotetraphenyl porphyrin and its derivatives including $\operatorname{TPPS}_{2 a}$ absorb across the visible spectrum with the longest wavelength peak at c. $650 \mathrm{~nm}$ but the strongest absorption peak is at c. $420 \mathrm{~nm}$ (Soret band), and exhibit red fluorescence $(600-720 \mathrm{~nm})(10,14)$. Cellular uptake and intracellular localisation of TPPS $2 a$ were studied in two separate experiments using fluorescence microscopy. Experimental details are described in the Supplementary Information. Initial screening studies were carried out with each cell line to determine appropriate concentrations of the TPPS ${ }_{2 a}$ and the cytotoxic agent, saporin (Sigma Aldrich). For the spheroid constructs the addition of drugs started on day 7. Cells were incubated separately with either TPPS 2 , in HEY cells at $0.4 \mu \mathrm{g} / \mathrm{mL}$ and for SKOV3 cells at $0.3 \mu \mathrm{g} / \mathrm{mL}$ (for 2D models and non-spheroid constructs) and $0.5 \mu \mathrm{g} / \mathrm{mL}$ (HEY) and $0.7 \mu \mathrm{g} / \mathrm{mL}$ (SKOV3) in the spheroid constructs, or saporin in the range of $10 \mathrm{nM}-40 \mathrm{nM}$ for 20 hours. Another set of cells were co-incubated with saporin and TPPS ${ }_{2 a}$ using the same concentrations for PCI. Cells were then washed with PBS and incubated for a further 4 hours with fresh medium without drug or photosensitiser. Afterwards, cells were illuminated for up to 7 minutes using a blue LumiSource ${ }^{\circledR}$ flatbed lamp with peak emission at $420 \mathrm{~nm}$ and $7 \mathrm{~mW} / \mathrm{cm}^{2}$ output (PCl Biotech, Oslo, Norway). Cell viability was evaluated at 48 hours (2D models, non-spheroid and spheroid constructs) or 96 hours (2D models and non-spheroid constructs) after light illumination using the Alamar Blue assay. Control groups with no drugs added and with or without light exposure were also assessed.

\section{$2.5 \quad$ Cell viability assay}

The cell viability of 2D monolayer cultures and 3D cancer constructs were determined using the Alamar Blue assay (Invitrogen, Thermo Fisher Scientific). Briefly, Alamar Blue dye solution (10\% of the total volume in cell culture medium) was added to the cells and incubated at $37^{\circ} \mathrm{C}$ for 4 hours. Afterwards, the supernatant from each well was 
transferred into black well plates. Fluorescence was measured following excitation at $530 \mathrm{~nm}$ and emission was detected at $620 \mathrm{~nm}$ with a fluorescence plate reader (Fluoroskan Ascent, Thermo Labsystems).

\subsection{Live-dead staining for fluorescence imaging}

It is important to corroborate the viability data measured for the constructs with other techniques to assess the treatment efficacy. At set time points following treatment, the 3D constructs were stained for viability imaging using the Live-dead viability kit (Molecular Probes, Thermo Fisher Scientific). 3D constructs were incubated with the Livedead solution containing $0.05 \%$ of $4 \mathrm{mM}$ Calcein-AM $\left(\lambda_{\mathrm{Ex} / \mathrm{Em}} 495 / 515 \mathrm{~nm}\right)$ and $0.2 \%$ of $2 \mathrm{mM}$ Ethidium homodimer-1 $\left(\lambda_{E x / E m} 495 / 635 \mathrm{~nm}\right)$ at room temperature for 30 minutes before imaging with an inverted fluorescence microscope (EVOS FL color, Life Technologies).

\subsection{Imaging hypoxia levels in spheroid constructs}

The reductions in oxygen levels within the cellular aggregates in the spheroid constructs of both cell lines were imaged using Image-iT Hypoxia reagent kit (488 nm excitation/ $610 \mathrm{~nm}$ peak emission, Molecular Probes by Life Technologies, Thermo Fisher Scientific) according to the protocol supplied by the manufacturer. Two $\mu \mathrm{l}$ of $1 \mathrm{mM}$ hypoxia reagent were added and mixed with $100 \mu \mathrm{l}$ of cell culture medium in each well. Imaging of the well plates was carried out with an inverted fluorescence microscope (EVOS FL color, Life Technologies). The emission intensity of this reagent correlates inversely to the oxygen partial pressure. Control constructs had cells incubated without the hypoxia reagent in normoxic conditions, and cells incubated with the hypoxia reagent in normoxic conditions.

\subsection{PDT/PCl phototoxicity studies in compressed 3D cancer constructs under hypoxic conditions}

Non-spheroid and spheroid 3D constructs of SKOV3 cells were prepared as above and incubated with TPPS $2 a$ $(0.3 \mu \mathrm{g} / \mathrm{mL})$ (non-spheroid) and $(0.7 \mu \mathrm{g} / \mathrm{mL})$ (spheroid) only, saporin (40 $\mathrm{nM}$ ) only or combination of saporin and TPPS $_{2 a}$ for 20 hours prior to washing with PBS. The constructs were then incubated for a further 4 hours with fresh medium without drug or photosensitiser in a hypoxia incubator (Innova co-48, New Brunswick ${ }^{\mathrm{TM}}$ scientific) with the oxygen partial pressure set at $1 \%$ prior to light exposure; the well plates were sealed just before light irradiation to prevent reoxygenation. The constructs were then exposed to blue light for 7 minutes, which under normoxia elicits a large reduction in viability. Monolayer and non-spheroid cultures underwent incubation with the drugs 24 hours post seeding whereas the spheroid cultures were treated 7 days after seeding.

\subsection{Apoptosis/necrosis in non-spheroid constructs}

The Annexin V-FITC apoptosis detection kit (Abcam) was used to investigate the initiation of necrosis and apoptosis in non-spheroid 3D cancer constructs treated with different conditions compared to non-treated controls. The cells were seeded at density of 75,000 cells (non-spheroid) or 50,000 cells (spheroids, HEY cells only) per construct and incubated for 24 hours (non-spheroid) or 7 days (spheroid) before undergoing treatment with either TPPS $2 a$ only 
( $0.3 \mu \mathrm{g} / \mathrm{mL}$ for SKOV3 cells and $0.4 \mu \mathrm{g} / \mathrm{mL}$ for HEY cells) (non-spheroids) or $(0.5 \mu \mathrm{g} / \mathrm{mL}$ ) (spheroids) for PDT only, saporin only $(20 \mathrm{nM})$, or a combination of both for $\mathrm{PCl}$ studies. The drugs were removed, and the constructs were washed with PBS 20 hours after the addition of drugs and were illuminated 4 hours later. Either 24 hours or 48 hours after illumination, $100 \mu \mathrm{l}$ of $1 \mathrm{X}$ Binding buffer was added per construct before adding $1 \mu \mathrm{L}$ of Annexin V-FITC $\left(\lambda_{\text {Ex/Em }}\right.$ $488 / 525 \mathrm{~nm})$ and $5 \mu \mathrm{L}$ of propidium iodide $(\lambda \mathrm{Ex} / \mathrm{Em} 535 / 617 \mathrm{~nm})$, to the buffer solution and incubating at room temperature for 5 minutes. The models were then imaged using a fluorescence microscope (EVOS FL color, Life Technologies).

\subsection{Evaluation of synergistic effects}

To evaluate whether a synergistic interaction between the two separate therapies applied, we used the following equation to calculate the value of alpha $(\propto)$ :

$$
\propto=\frac{F_{P D T} x F_{\text {cytotoxin }}}{F_{\text {combination }}} \quad \text { equation } 1
$$

In the numerator of equation 1, the terms $F_{P D T}$ and $F_{\text {cytotoxin }}$ designate the fractional viability for each separate therapy, PDT and the application of the cytotoxin, and the denominator is the fractional viability observed following the PCI combination treatment. If $\alpha>1$ then a synergistic effect is present whereas an antagonistic effect is denoted by $\alpha<$ 1. This analysis has been used previously by us and others to identify synergistic effects (21) (39) (40). To assess the $\mathrm{PCl}$ efficacy versus cytotoxin alone, we calculated the ratio of the viability without $\mathrm{PCl}$ (i.e. cytotoxin alone) divided by the viability measured after PCI. Likewise, to assess the PCI efficacy versus PDT alone, we calculated the ratio of the viability with PDT divided by the viability measured after PCI.

\section{$2.11 \quad$ Statistical analysis}

Results were analysed using 2-way ANOVA with post-hoc analysis and values of $p<0.05$ were considered to be statistically significant. Error bars from the mean show +/- standard deviation (SD).

\section{Results}

\subsection{Manufacture of 3D compressed ovarian cancer collagen constructs}

The compressed 3D culture system consists of a cell-embedded Type 1 collagen matrix that has undergone plastic compression through the use of fluid absorbers producing constructs with a thickness of c. $200 \mu \mathrm{m}$ (collagen density, $9.6 \%$ ) in wells of a 96 well plate (38). This system creates a realistic biomimetic 3D model, which represents a more biomimetic in vivo environment due to the high collagen density (37). Two different 3D constructs (non-spheroid and spheroid) were generated for both HEY and SKOV3 ovarian cancer cell lines. The short-term non-spheroid constructs generally consisted of dispersed single cells. In the longer-term spheroid constructs the cells were allowed to 
proliferate and develop into spheroids prior to undergoing treatment. The constructs in our study contained multiple spheroid aggregates of differing dimensions. The aggregate formation of SKOV3 and HEY cells were monitored on days 3,5 and 7 and were found to develop into measurable spheroid cellular aggregates by day 7. Phalloidin/ Hoechst staining was also used as it allows the structure of the spheroids together with their destruction from treatment to be visualised. For each cell line, sample areas of multicellular aggregates (typically 20-30 per construct) from 4-5 constructs were measured using the ImageJ software and categorised into small, medium and large aggregates as shown in Table S1. Figure 1 shows examples of small and large spheroids of SKOV3 cells. The aggregated structure of the larger spheroid that develops after 7 days is apparent. HEY cells generally formed a higher proportion of larger spheroids compared to SKOV3 cells. Although irregular in shape they approximate to a circular shape, so the approximate diameters can be estimated using the cross-sectional area. The small (approximately $<50 \mu \mathrm{m}$ in diameter) and medium (100-150 $\mu \mathrm{m}$ ) aggregates predominated (over 50\% of total sampled) in the SKOV3 constructs whereas the medium and large (approximately $>150 \mu \mathrm{m}$ ) predominated in the HEY constructs.


Figure 1: Examples of small (left) and large (right) spheroids of SKOV3 cells formed 7 days after seeding. The cytoskeletal structure of the cells in the aggregates was stained with Alexa Fluor 488 Phalloidin (Green) and the nucleus of cells was stained with Hoechst dye (Blue). The scale bar presented in each image is $60 \mu \mathrm{m}$.

\subsection{PCl effects in 2D and non-spheroid 3D cancer constructs}

The fluorometric Alamar blue cell viability assay was used to assess cell viability since light scattering from the collagen gel precludes the use of optical absorbance. 2D monolayer cultures were initially used in the study for later comparison to the 3D constructs. Preliminary PDT studies were carried out to identify the correct photosensitiser/light doses to achieve sub-lethal phototoxicity required for subsequent $\mathrm{PCl}$ experiments. These studies revealed that TPPS $_{2 a}$ at concentrations $0.3 \mu \mathrm{g} / \mathrm{mL}$ and $0.4 \mu \mathrm{g} / \mathrm{mL}$ were appropriate for conducting PCl studies in 2D and 3D cultures of SKOV3 and HEY cells respectively. Fluorescence microscopy results show that in the treated 3D constructs, the TPPS $2 a$ was taken up by the cells rather than becoming bound in the collagen. The control collagen constructs with cells but without photosensitiser showed negligible autofluorescence levels (Figure S2). Figure S3 shows the uptake of TPPS $2 \mathrm{a}$ in non-spheroid 3D constructs SKOV3 and HEY cells, which were additionally stained with LysoTracker Green to provide further evidence for intracellular uptake of the TPPS $2 \mathrm{a}$ in the 3D constructs. The percentage viabilities of each cell line after PCI treatment in 2D cultures as well as the PCl efficacies compared to PDT or saporin alone were measured at 48 or 96 hours after illumination. Figure $2(A-F)$ shows the mean percentage viabilities of 
both cell lines in the 3D constructs after each treatment compared to the control for two concentrations of saporin, 10 and $20 \mathrm{nM}$ at 48 and 96 hours after illumination.


Figure 2: Percentage viability of HEY (A, C, E) and SKOV3 (B, D, F) cells in non-spheroid 3D compressed collagen constructs after treatment with PDT, saporin only and PCl. Constructs for graphs (A and B) were treated with $10 \mathrm{nM}$ saporin, $(\mathrm{C}$ and $\mathrm{D})$ with $20 \mathrm{nM}$ saporin and assay at 48 hours incubation post illumination; ( $E$ and F) with $20 \mathrm{nM}$ saporin and assay at 96 hours incubation post illumination. ${ }^{*} \mathrm{p}<0.05,{ }^{* *} \mathrm{p}<0.01$ and ${ }^{* * *} \mathrm{p}<0.001$.

$\mathrm{PCl}$ enhanced cell kill was observed for both HEY and SKOV3 cells in 2D cultures using 10 and $20 \mathrm{nM}$ of saporin after 3, 5 or 7 minutes of light exposure (Table S2). The corresponding data for 3D cultures are tabulated in Table S3. The alpha values were calculated to confirm that a synergistic PCl effect took place (see 2.10). Using 20 nM saporin at 48 hours post-illumination and 3, 5 and 7 minutes illumination, the alpha values for SKOV3 cells were 
2.6, 2.7 and 3.9, and 2.8, 3.2 and 4.6 for the HEY cells, in accord with a greater then unity synergistic effect. Comparison of the data for $3 \mathrm{D}$ vs. $2 \mathrm{D}$ culture shows that $\mathrm{PCl}$ efficacy vs. PDT was lower in $3 \mathrm{D}$ cultures than the $2 \mathrm{D}$ culture for both cell lines, most notably using the lower $10 \mathrm{nM}$ saporin concentration and shorter 3 and 5 minutes illumination times. Upon increasing the saporin concentration to $20 \mathrm{nM}$, the $\mathrm{PCl}$ treatment induced a more substantial decrease in cell viability from $92 \%$ to $21 \%$ compared to saporin only after 5 minutes of irradiation in the SKOV3 3D cultures (Figure 2D). In the same cell line, the PCl efficacies versus PDT alone and saporin alone after this irradiation period were 3 and 5 -fold higher $(\mathrm{P}<0.001)$ giving a synergistic alpha value of 2.5. Likewise, with the HEY 3D cultures (Figure $2 \mathrm{C}$ ) a significant reduction in cell viability was observed with $\mathrm{PCl}$ treatment and longer irradiation periods. Compared to saporin only, cell viability in the PCI treated HEY 3D culture was lowered from $96 \%$ to $23 \%$ after 5 minutes irradiation with the PCl efficacies being 2 and 4 versus PDT alone and saporin alone $p<0.001$. For the same illumination period this cell line produced a lower synergistic alpha value of 1.8 compared to SKOV3 cells.

SKOV3 cells, (10nM saporin), 48 hours post illumination

SKOV3 cells, (20nM saporin), 48 hours post illumination

SKOV3 cells, (20nM saporin), 96 hours post illumination

HEY cells, (10nM saporin), 48 hours post illumination

HEY cells, (20nM saporin), 48 hours post illumination 96 hours post illumination

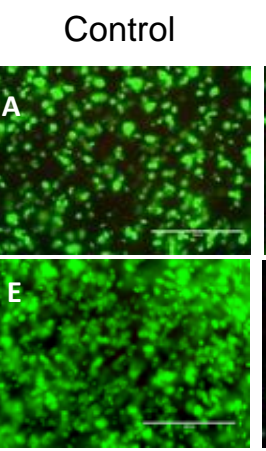

PDT
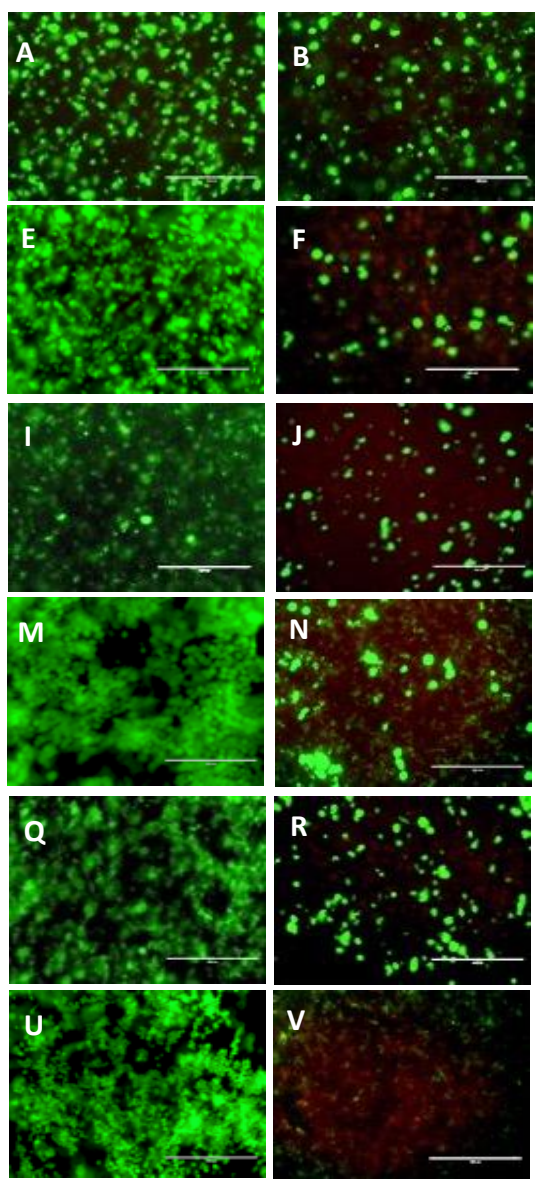

Saporin only
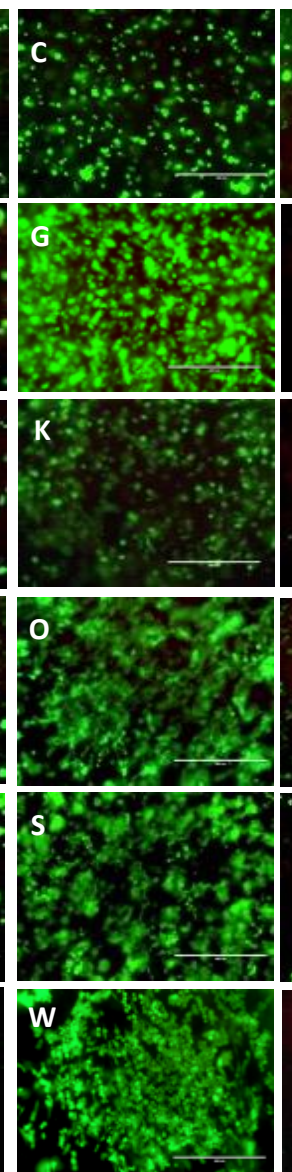

$\mathrm{PCl}$
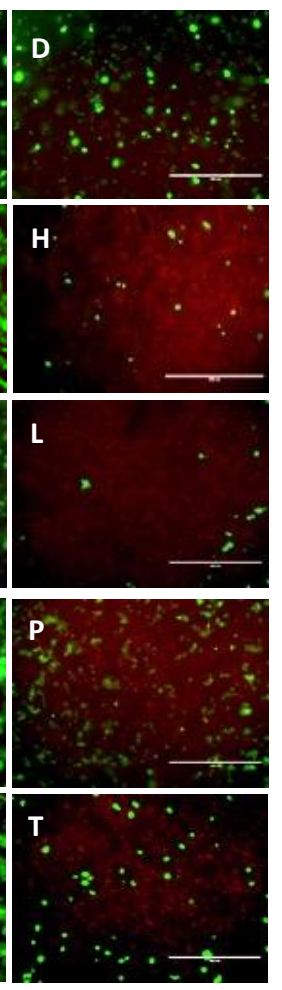

$\mathrm{x}$

Figure 3: Live-dead images of non-spheroid 3D compressed collagen constructs of SKOV3 (A-L) and HEY (M-X) cells after undergoing treatment with TPPS $2 a$ only $(0.3 \mu \mathrm{g} / \mathrm{ml}$ for SKOV3 cells) $(\mathrm{B}, \mathrm{F}, \mathrm{J})$ and $(0.4 \mu \mathrm{g} / \mathrm{ml}$ for HEY cells) (N, R, V), saporin only at concentrations of $10 \mathrm{nM}(\mathrm{C}$ and $\mathrm{O}), 20 \mathrm{nM}$ incubated for 48 hours post illumination $(\mathrm{G}$ and $\mathrm{S})$ or 96 hour post illumination (K and $\mathrm{W}$ ) and a combination of both drugs $(\mathrm{D}, \mathrm{H}, \mathrm{L}, \mathrm{P}, \mathrm{T}, \mathrm{X})$ following 5 minutes illumination period. Constructs $(\mathrm{A}-\mathrm{H})$ and $(\mathrm{M}-\mathrm{T})$ were incubated for 48 hours post illumination, constructs (I-L) and (U-X) were incubated for 96 hours post illumination. 3D constructs were incubated with the Live-dead solution containing Calcein- AM to stain live cells (green) and Ethidium homodimer1 to stain dead cells (red). The scale bar presented in each image is $400 \mu \mathrm{m}$. 
In a further set of experiments 2D and 3D cultures of both cell lines treated with saporin $20 \mathrm{nM}$ were subjected to an extended incubation period of 96 hours post-illumination prior to terminating the experiment and the viability assays. A significantly higher cytotoxic activity was observed compared to cultures, which were exposed to the same concentration of saporin using the shorter 48-hour incubation post-illumination period. In the 3D cultures, the alpha values calculated for each ascending illumination period were 3.7, 3.0 and 3.2 in HEY cells and 2.4, 3 and 7.4 in SKOV3 cells. The 3D cultures of both cell lines in our study were subjected to Live-dead staining to provide further evidence for the PDT and PCl effect on the 3D constructs. The Live-dead kit distinguishes live cells from dead cells through the use of green fluorescent calcein AM stain which indicates intracellular esterase activity in live cells and red fluorescent ethidium homodimer-1 stain which indicates plasma membrane integrity loss in dead cells. Figure 3 shows Live-dead images of HEY and SKOV3 3D cultures following PCl treatments using $20 \mathrm{nM}$ saporin and 5 minutes illumination period. The Live-dead assay results are consistent with the cell viability analysis where a lower number of live cells are present after PCI treatment compared to PDT or saporin alone.

\section{3 $\quad \mathrm{PCl}$ effects in spheroid 3D constructs}

The PCl experiments were carried out on mature spheroid 3D compressed constructs of both cell lines, which more closely imitate tumour models in terms of morphology and dimensions. In these constructs the cells were allowed to develop into spheroids within the compressed collagen matrix for 7 days after initial seeding. Pilot PDT experiments indicated that the concentrations of TPPS2a, which induced sub-lethal PDT effects, were $0.5 \mu \mathrm{g} / \mathrm{mL}$ in HEY cells and $0.7 \mu \mathrm{g} / \mathrm{mL}$ in SKOV3 cells, which are higher than employed for the non-spheroid studies. The spheroid constructs of the HEY cells displayed significant PCl effects using $20 \mathrm{nM}$ saporin with the mean viabilities decreasing from $98 \%$ to $30 \%, 97 \%$ to $24 \%$ and $97 \%$ to $19 \%$ compared to saporin only treatment and the $\mathrm{PCl}$ efficacies being 2.5 and 3.3 (3 minutes), 1.9 and 4.1 (5 minutes) and 2 and 5.2 (7 minutes) fold higher than using PDT or saporin only for each irradiation period respectively. Synergistic alpha values of 2.5, 1.9 and 2 were calculated for 3,5 and 7 minutes light exposure respectively. In contrast, spheroid constructs of the SKOV3 cells exhibited no significant PCI effects using $20 \mathrm{nM}$ of saporin, however upon increasing the concentration of saporin to $40 \mathrm{nM}$, the mean viabilities were significantly reduced from $97 \%$ to $41 \%$ (3 minutes), $91 \%$ to $39 \%$ (5 minutes) and $92 \%$ to $31 \%$ ( 7 minutes) compared to saporin only therapy for each irradiation period, as shown in Figure 4A. A significant PCl effect was observed after all illumination periods compared to saporin alone, however compared to PDT alone, a significant effect was only observed after 3 minutes of irradiation with the PCl efficacy being 1.7-fold higher than PDT (alpha value of 1.7). In addition to the Alamar blue viability analysis, Phalloidin/ Hoechst staining allows the structure of the spheroids and the impact of treatment to be visualised, as shown in Figure 4B, after 3 minutes of illumination. Spheroid destruction 
after PCI (IV and VIII) was greater than models treated with PDT (II and VI) or saporin alone (III and VII) in both cell lines. In addition, Live-dead staining of the HEY and SKOV3 cell spheroids was carried out to confirm the effects of the treatment on the spheroids as shown in Figure S4.

A

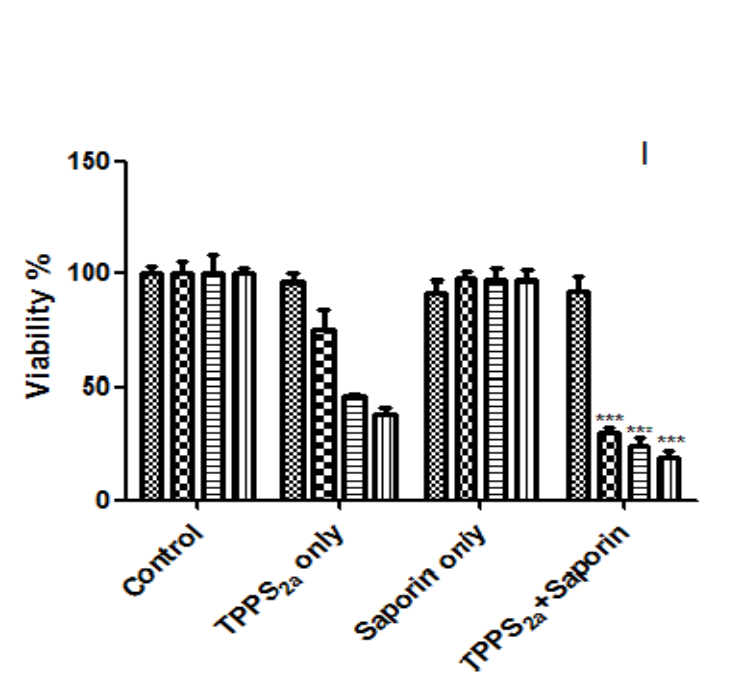

Treatments applied in combination or alone

B

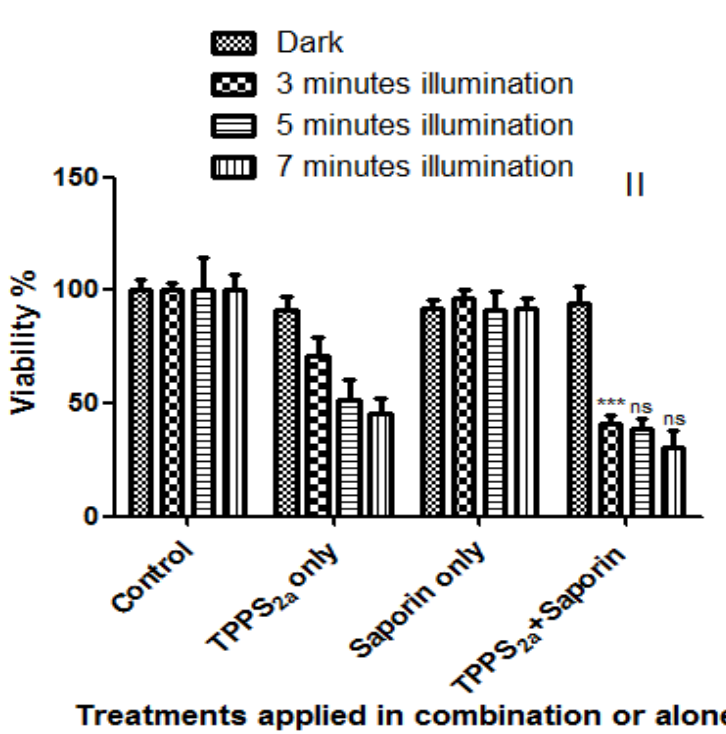

Control
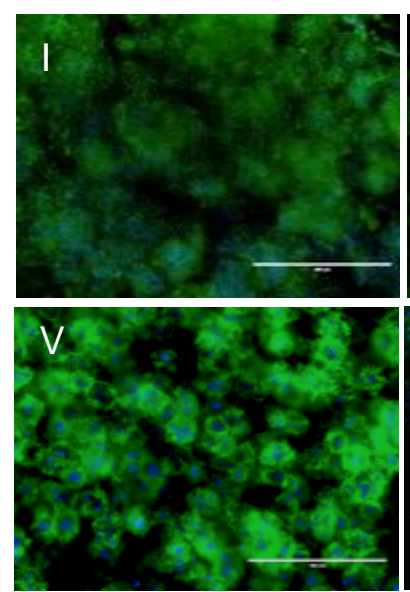

PDT
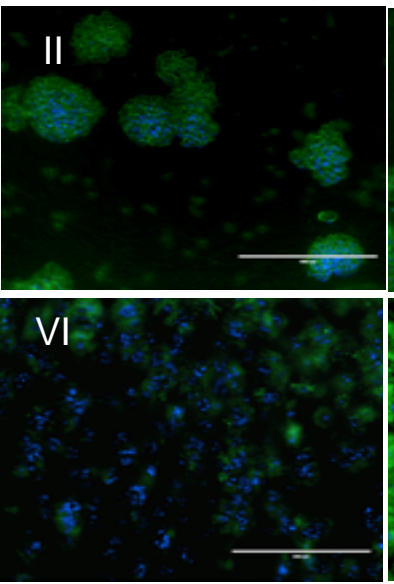

Saporin only
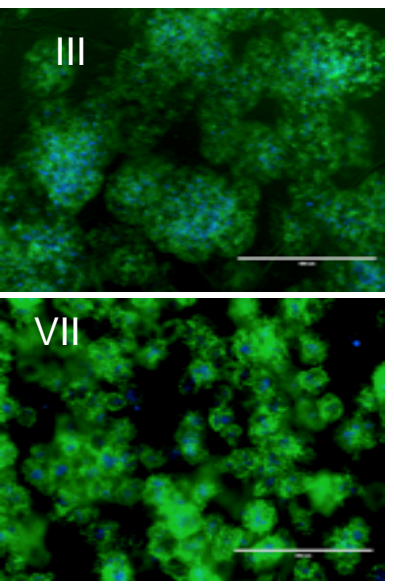

$\mathrm{PCl}$


Figure 4: A: Percentage viability of HEY (I) and SKOV3 (II) cells spheroid 3D compressed collagen constructs after treatment with PDT, saporin only and PCI. Constructs for the SKOV3 cells were treated with TPPS $2 \mathrm{a}(0.7 \mu \mathrm{g} / \mathrm{ml})$ and $40 \mathrm{nM}$ saporin, and for the HEY cells with TPPS $2 \mathrm{a}(0.5 \mu \mathrm{g} / \mathrm{ml})$ and $20 \mathrm{nM}$ saporin. The constructs were incubated for 48 hours post illumination before terminating the experiment using Alamar Blue assay. ${ }^{* *} p<0.001$. These $p$ values show the significance difference between PDT and PCI treatments; B: Phalloidin/ Hoechst stained images of spheroid constructs of HEY (I- IV) and SKOV3 (V-VIII) cells upon treatment with PDT alone using TPPS2a at concentrations $0.5 \mu \mathrm{g} / \mathrm{ml}$ (II) and $0.7 \mu \mathrm{g} / \mathrm{ml}$ (VI), saporin alone at concentrations 20 $\mathrm{nM}$ (III) and $40 \mathrm{nM}$ (VII) and PCI (IV and VIII) after 3 minutes of illumination. A reduced number of spheroids is evident when TPPS $_{2 a}$ and saporin are combined compared to using each drug alone. For PCl of HEY the arrow highlights a fragmented pattern of cell aggregates (IV). Alexa Fluor 488 phalloidin (green) was used to stain the cytoskeletal structure of the cells and Hoechst 33258 (blue) was used to stain the nuclei. The scale bar presented in each image is $400 \mu \mathrm{m}$. 
The aim of this experiment was to compare the effect of normoxia (20\% oxygenation) and hypoxia (1\%) on PDT and $\mathrm{PCI}$ on SKOV3 cells since both rely on the generation of reactive oxygen species. We used the highest light dose (7 mins) in order to discern the relative responses to the oxygenation changes. As shown in Figure $5 \mathrm{~A}$ for the nonspheroid constructs, PDT was ineffective under hypoxia and no significant decrease in cell viability was observed. $\mathrm{PCl}$ elicited a small reduction in mean viability to $82 \%$ in the non-spheroid cultures vs. $96 \%$ in the spheroids cultures. Using saporin alone, comparable small reductions in viability were observed for both normoxia and hypoxia. The Live-dead assay images shown in Figure 5B recorded after PDT/PCI using hypoxic constructs are in accord with the viability data. From these data, it is apparent that both PDT and PCI were strongly inhibited at artificially induced low oxygenation levels. The same applies to the treatment of SKOV3 spheroid constructs, as shown in Figure S5 with no significant differences apparent in the viabilities or Live-Dead assay images under hypoxia vs. the controls. In contrast for the 2D culture under hypoxia, there were significantly larger effects for both PDT and PCI treated cells, with mean viability reduced to $78 \%$ for $\mathrm{PDT}$ and $38 \%$ for $\mathrm{PCl}$ (Figure S5). Comparison with the $2 \mathrm{D}$ data under normoxia suggests that the $\mathrm{PCl}$ effect was more strongly inhibited under hypoxia than for PDT alone.

A

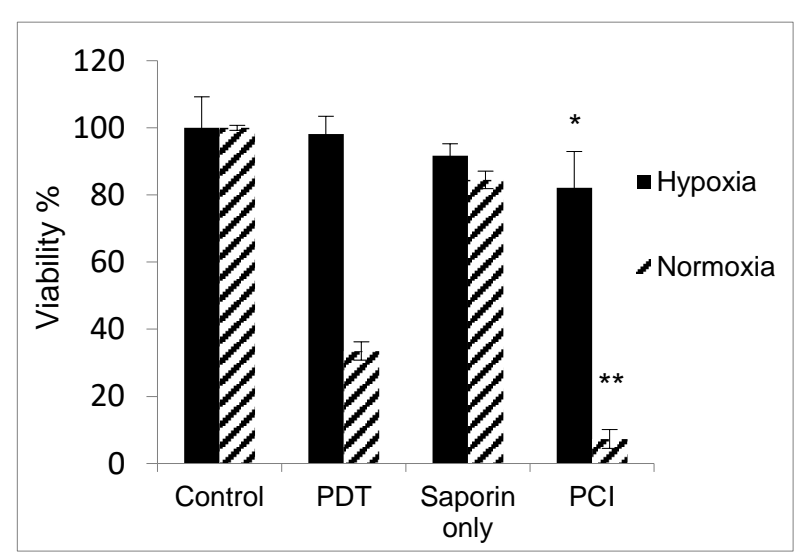

C

Day 1
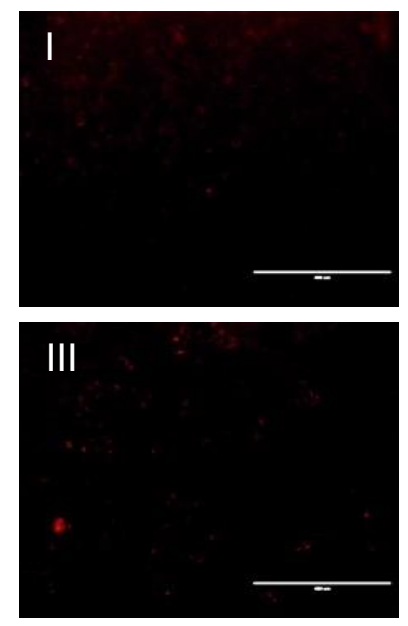

$\mathrm{B}$

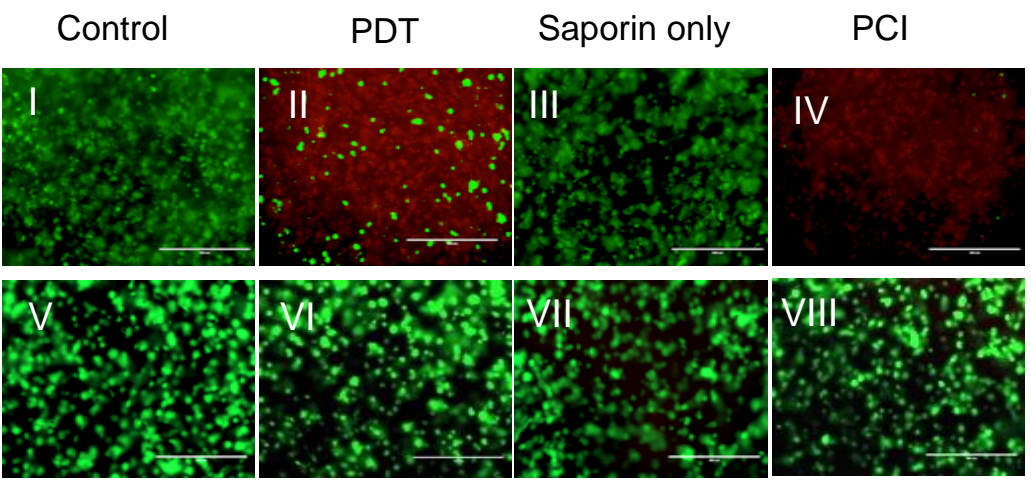

Figure 5: Effect of hypoxia on PCl and PDT. A. Percentage viability of SKOV3 cell 3D non-spheroid constructs after $\mathrm{PCl}$ treatment in normoxic condition compared to hypoxic condition using TPPS ${ }_{2 a}$ only $(0.3 \mu \mathrm{g} / \mathrm{ml})$ only for PDT, saporin $40 \mathrm{nM}$ only and a combination of both drugs for $\mathrm{PCl}$ as well as a light irradiation period of 7 minutes. Alamar Blue assay was carried out 48 hours after exposure to light; B. Livedead images of SKOV3 cell non-spheroid constructs after PCl treatment in normoxic condition (I-IV) compared to hypoxic condition (V-VIII); C. Imaging reduction of oxygenation in SKOV3 cells (I-II) and HEY cells (III-IV), as spheroids form on day 7 (II and IV), compared to one day post seeding before the formation of spheroids (I and III), The hypoxia levels within the spheroids were measured using the Image$\mathrm{iT}^{\mathrm{TM}}$ Red Hypoxia reagent. The emission intensity correlates inversely with the oxygen partial pressure. The scale bar presented in each image is $400 \mu m .{ }^{*} p<0.05,{ }^{*} p<0.01$. The $p$ values show the significance difference between PDT and PCI. 
Oxygenation levels in 3D constructs of both cell lines were imaged on day 1 and 7 and after seeding using the ImageiT hypoxia reagent. The reagent is live cell permeable and consists of a fluorogenic compound, which is weakly fluorescent in normoxic environments including live cells but becomes strongly fluorescent as the $\mathrm{O}_{2}$ concentrations decrease. Figure $5 \mathrm{C}$ shows a comparison of images for each cell line obtained on day 1 vs. day 7 using the same intensity scale. On day 7 the fluorescence intensity is higher which corresponds to lower oxygenation (II and IV) levels being present in the SKOV3 and HEY spheroids. These results are consistent with the lack of sufficient diffusion of $\mathrm{O}_{2}$ into the larger spheroid constructs compared to the non-spheroid constructs (I and III).

\subsection{Stimulation of apoptotic cell death in PCl treated non-spheroid 3D constructs}

To determine the occurrence and level of apoptosis induced upon treatment with $\mathrm{PCl}$ and the controls, the nonspheroid 3D constructs were stained with Annexin V (for detection of apoptosis- shown in green) and Propidium iodide (for detection of necrosis - shown in red) either 24 hours or 48 hours after illumination. As shown in Figure 6 , for both cell lines a stronger apoptotic effect can be seen in constructs treated with $P C l(D, H, L$ and $P)$ than those treated with $\mathrm{TPPS}_{2 a}(\mathrm{PDT})(\mathrm{B}, \mathrm{F}, \mathrm{J}$ and $\mathrm{N})$ or saporin $(\mathrm{C}, \mathrm{G}, \mathrm{K}$ and $\mathrm{O})$ only. In contrast, the necrotic effect observed in constructs treated with PDT only is noticeably higher than those treated with $\mathrm{PCl}$ or saporin only. Furthermore, a greater apoptotic effect is observed at 48 hours ( $H$ and $P$ ) compared to 24 hours ( $D$ and $L$ ). Such staining was also carried out on spheroid constructs of HEY cells which underwent PCl treatment using TPPS $2 \mathrm{a}(0.5 \mu \mathrm{g} / \mathrm{ml})$ and saporin (20nM) (Figure S6) and showed that a higher level of necrosis can be detected in PDT treated samples (B and F) than $\mathrm{PCl}$ treated samples $(\mathrm{D}$ and $\mathrm{H})$. In contrast, apoptosis appears to predominate in PCl treated constructs (D and H) than PDT treated constructs (B and F). Furthermore, in the PDT treated constructs a greater degree of necrosis can be observed 48 hours after illumination (F) compared to 24 hours post illumination (B). In the PCl treated constructs on the other hand, the degree of both necrosis and apoptosis is greater in constructs incubated for 48 hours post illumination $(H)$ than those incubated for 24 hours post illumination (D). In comparison to non-spheroid constructs, some apoptosis could be observed in PDT treated spheroid constructs. Furthermore, an overall higher level of necrosis and apoptosis can be seen in spheroid constructs than in non-spheroid constructs. 
Control

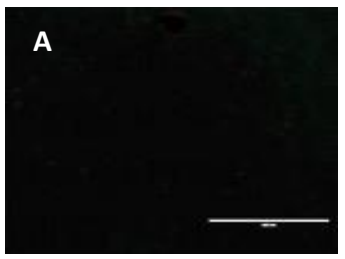

SKOV3 cells, 48 hours post illumination

HEY cells, 24 hours post illumination

HEY cells 48 hours post illumination
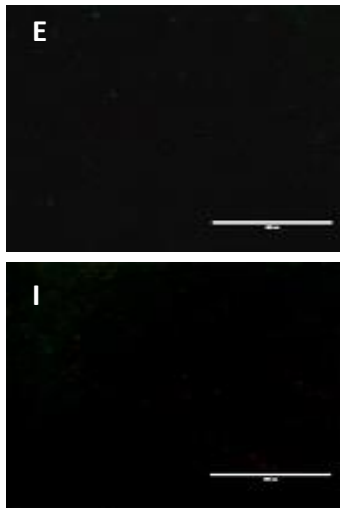

PDT
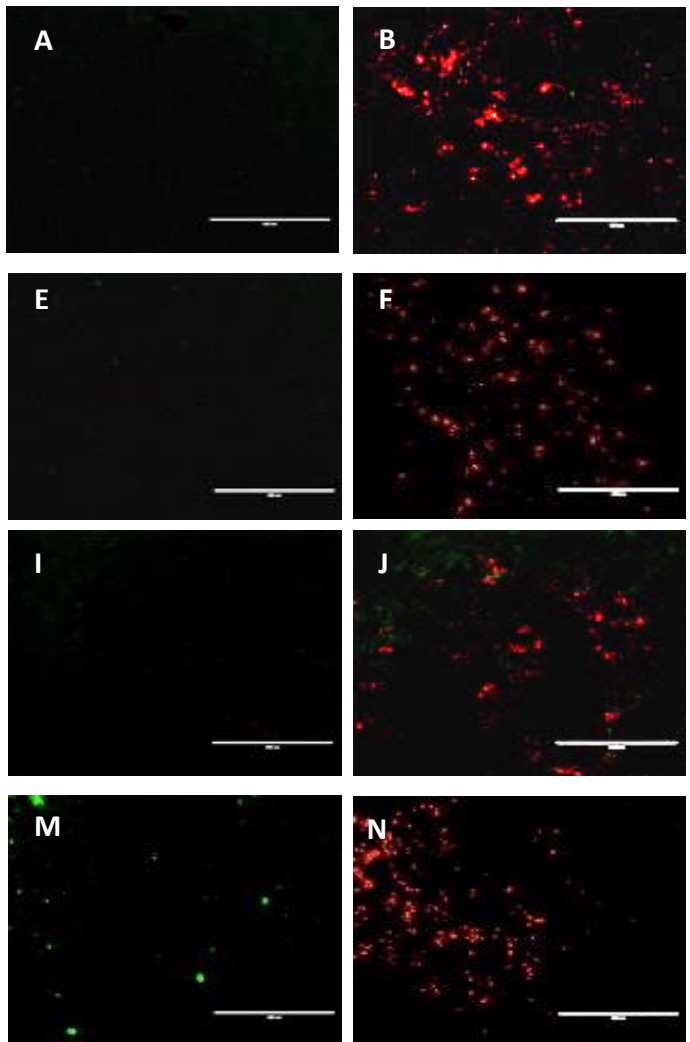

Saporin only
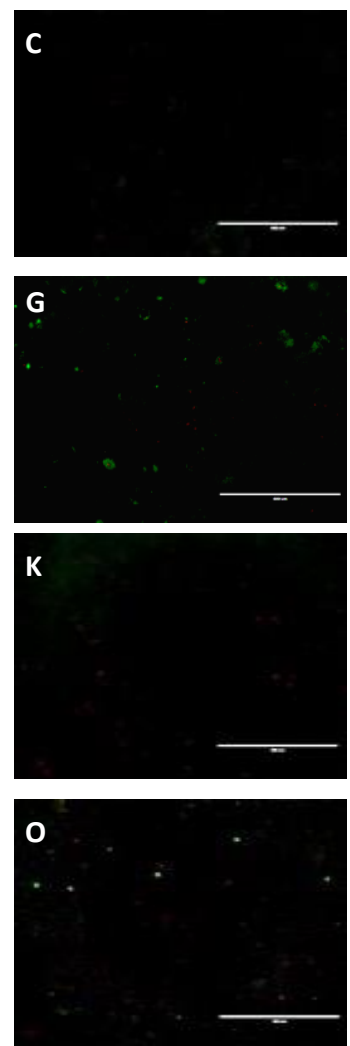

$\mathrm{PCl}$
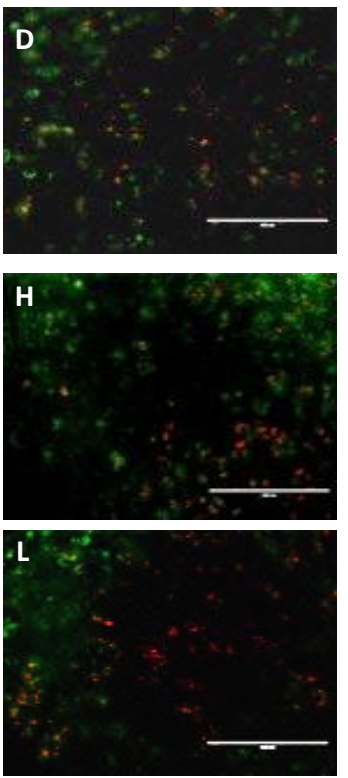

Figure 6: Apoptotic and necrotic induced cell death in 3D compressed constructs of SKOV3 and HEY cells. Comparison of cell death pathways induced after PCI compared to PDT or saporin alone in non-spheroid constructs of SKOV3 (A-H) and HEY (I-P) cells at 24 hours (A-D) and (I-L) and 48 hours post illumination (E-H) and (M-P) have been shown. In PDT only treated constructs TPPS $2 a$ was used at concentrations of $0.3 \mu \mathrm{g} / \mathrm{ml}$ in SKOV3 cells (B and F) and $0.4 \mu \mathrm{g} / \mathrm{ml}$ in HEY cells ( $\mathrm{J}$ and N). The saporin concentration used in this experiment was $20 \mathrm{nM}$. The constructs were illuminated for 7 minutes. Annexin V- was used to indicate apoptosis (green) and propidium iodide was used to indicate necrosis (red). The scale bar represents $400 \mu \mathrm{m}$.

\section{Discussion}

In this study we have compared the efficacy of photochemical internalisation of a macromolecular cytotoxin, saporin, on two ovarian carcinoma lines grown in $2 \mathrm{D}$ and in $3 \mathrm{D}$ compressed collagen constructs. The $3 \mathrm{D}$ studies also examined the treatment efficacy at two different times after cell seeding in the constructs. Magdeldin et al. (2014) (37) and Lopez-Davila et al. (2016) (41) from our laboratory used the same system to develop 3D models of colorectal cancer (HT29 and HCT116 cells). Both cell lines used here developed aggregates of cells or spheroids by day 7 with HEY cells forming larger spheroids than SKOV3 cells (Figure 1). A characterisation study by Lee et al. (2013) on 3D spheroid models of epithelial ovarian cancer cell lines grown on $1.5 \%$ polyHEMA coated well plates for up to 14 days revealed that SKOV3 and HEY cells formed large and tightly packed spheroids that were $200-800 \mu \mathrm{m}$ in diameter (42). This study also used a classification system to introduce three categories (large dense aggregates, large loose aggregates and small aggregates) for describing the shapes of aggregates, which we have adapted for the present study. Although the cultures presented in our study were only allowed to grow into spheroids for 7 days compared to the 14 day period used in their study, the sizes of the spheroid aggregates presented in the large 
category (Table S1) were either close to or within the range of the measurements described by Lee et al. (42), despite the difference in the method of preparing the constructs. In a related study but different ovarian carcinoma cell line, Celli et al. (2014) (27) used the OVCAR5 cell line to grow micronodules on Matrigel to study the effect of PDT using Verteporfin. The diameter range of 'micronodules' formed was between 30-450 $\mu \mathrm{m}$ with the majority being above $200 \mu \mathrm{m}$, which makes them generally larger than the spheroids formed in our study.

\section{1 $\quad \mathrm{PCl}$ effects in non-spheroid 3D constructs}

$\mathrm{PCl}$ was effective in both 2D and short-term 3D non-spheroid cultures using similar treatment conditions (saporin, photosensitiser and light doses) to our previous studies (21). However, whilst there were similar enhancements in the PCl efficacies of both cultures compared to PDT only, 2D monolayer cultures showed higher PCl efficacies than 3D cultures in comparison to treatment with saporin alone (Table S2 and S3). For example, in HEY cells, (5 minutes illumination, 48 hours post-illumination) the $\mathrm{PCl}$ efficacies compared to saporin only (20nM) for 2D and 3D were 8 vs. 4 respectively. The enhancement was more pronounced following 96-hour incubation post-illumination. In addition, a Live-dead imaging assay was performed (Figure 3) and the results confirmed the efficacy of PCI compared to treatment with saporin alone. A previous study in 2D culture by Fretz et al. (2009) (43) also showed that PCl treatment using saporin, in the human ovarian cancer cell line OVCAR-3 was effective. In their study, reduction in cell viability over a range of saporin doses at a fixed light dose were investigated, whereas in this study we have also varied the light dose. $\mathrm{PCI}$ treatment of SKOV3 cells has also been shown to be effective in 2D with a targeted recombinant fusion toxin incorporating another Type 1 ribosome-inactivating protein toxin, gelonin (3).

A few other studies have examined PDT or PCI in Type 1 collagen constructs but without the plastic compression step used here to form constructs with a comparable collagen density to that found in tissue (35) (44). O'Rouke et al. (2017) (35) tested the sensitivity of neurons and glia to PCl using either a chlorin (TPCS $2 a$ ) or the same porphyrin, TPPS $2 \mathrm{a}$, and bleomycin (chemotherapeutic drug) compared to PCI30 cells (head and neck squamous cell carcinoma). The results showed that neurons have a higher resistance towards $\mathrm{PCI}$ treatment than $\mathrm{PCl} 30$ cells and can survive conditions that are adequate for destroying tumour cells such as those induced by PCI. Martinez et al. (2017) (21) examined the effect of PCl using TPCS $_{2 a} /$ TPPS $_{2 a}$ (photosensitiers) and saporin (chemotherapeutic drug) on PC3 and MatLyLu prostate carcinoma cells. Live- dead assay images showed that PCl was effective in the $3 \mathrm{D}$ model and led to changes in morphology with cells adopting a more rounded shape after treatment.

In our study increasing the incubation post illumination period to 96 hours resulted in a significantly higher cytotoxic activity than their counterparts, which were exposed to the same concentration of saporin but a shorter incubation post-illumination period (48 hours). Apoptosis is a slower process than necrosis $(45,46)$ therefore 
elongating the incubation time after illumination to 96 hours can elicit a greater reduction in cell viability compared to incubating for shorter times prior to termination of the experiment. In our study with saporin PCl on prostate carcinoma lines we also observed improved efficacy at 96 hours vs. 48 hours (21), as observed in other studies (47).

As shown in Figure 6, we found that apoptosis predominated over necrosis in PCl treated non-spheroid constructs, and likewise for spheroid constructs (Fig. S6); in contrast, necrosis was predominant in PDT treated counterparts. In 2D PCl experiments, apoptosis was also observed using $\mathrm{AlPcS}_{2 a}$ as a photosensitiser and dichloroplatinum (DP) as the chemotherapeutic drug (8). Intracellular localisation of the photosensitiser is a key factor in determining the nature of cell death as being necrotic or apoptotic $(48,49)$. Photosensitisers that localise in mitochondria or ER tend to stimulate apoptosis whereas localisation within the plasma membrane or lysosomes tends to promote necrosis of cells such as TPPS 2 (50), as observed here. Saporin also functions by inducing apoptosis via mitochondrial cascade (51). PCl using saporin is therefore expected to cause cell death mainly through apoptosis, which is consistent with our data.

\subsection{PCl effects in spheroid 3D constructs}

We then examined the $\mathrm{PCl}$ efficacy in the longer-term spheroid constructs and found that the treatment was still effective but that reductions in viability were lower for all conditions studied compared to non-spheroid constructs. Moreover, differences in response emerged between the two cell lines studied. For HEY spheroid constructs, the $\mathrm{PCl}$ efficacy ratio vs. saporin alone at $20 \mathrm{nM}$ was lower than that observed in their non-spheroid counterparts using the same concentration of saporin. This was particularly evident at the longer illumination times, where for 7 minutes illumination, the ratio is 8 for non-spheroid constructs compared to only 5 for spheroid constructs. However, for SKOV3 spheroid constructs, the concentration of saporin had to be increased to 40nM for significant treatment efficacy to be attained and the reduction in viabilities were still lower than for the HEY spheroids with 7 minutes illumination yielding a $\mathrm{PCl}$ efficacy ratio of only 3. Live-dead and Phalloidin/Hoechst vital imaging confirmed the impact of the treatment (Figures 4 and S4). In a previous study on F98 glioma spheroids, PCI using bleomycin and aluminium disulfonated phthalocyanine as the photosensitiser was shown to be effective with $25 \%$ of cells remaining viable following treatment (40).

A key finding from our study is that better PCI therapeutic efficacy was observed in the HEY spheroid constructs compared to the SKOV3 spheroid constructs for all illumination periods despite their propensity to form larger aggregates compared to SKOV3 cells. This result is unexpected, as discussed further later, since drug penetration into larger aggregates should be more restricted thereby lowering efficacy. In general, there are several possible factors that could render spheroids to be more resistant to $\mathrm{PCl}$. The spheroid sizes used herein are similar to the study by Lee et al. (2013) as discussed above where it was shown that HEY and SKOV3 cells tend to form 
large dense aggregates (42). In relation to our study, the large and dense nature of the aggregates may restrict drug uptake and therefore PCl efficacy compared to the non-spheroid 3D models and could explain the need to double the concentrations of the saporin (to $40 \mathrm{nM}$ ) required to treat both HEY and SKOV3 spheroid constructs compared to their non-spheroid counterparts. Although we used relatively long incubation times of 20 hours, it is relevant to note that we also had to employ higher photosensitiser concentrations in the spheroids to achieve the sub-lethal PDT effect for initiating PCl. However, this does not explain the lower sensitivity of SKOV3 spheroid constructs to PCI than the generally larger HEY counterparts, even though a slightly lower photosensitiser dose was used with the HEY constructs. A possible explanation is that that the HEY spheroids have a more porous sub-structure which enables the compounds to penetrate more efficiently albeit this was not apparent from the imaging studies. Growth in the 3D microenvironment will result in phenotype changes such as gene expression which could account for the difference in response to $\mathrm{PCl}$ (52). No systematic studies have been reported for these cell lines as far as we are aware on phenotypic changes in 3D models, but a comparative study on changes in fibronectin expression in SKOV3 and HEY spheroids vs. 2D reported similar results for both cell lines (53). The resistance to PCl-induced damage found in the spheroid constructs does present a challenge in terms of drug delivery since higher doses of the photosensitiser and cytotoxin were required which suggests that drug delivery and co-localisation are impaired. Therefore, consideration to improved co-delivery methods should be examined, for example the use of photosensitiser-drug conjugates, so that efficient co-localisation needed for $\mathrm{PCl}$ can be achieved.

There are other factors that adversely affect PDT efficacy in 3D as cells grow and form spheroids. With the higher cell density present in spheroids, the local rate of oxygen consumption increases creating a more hypoxic environment, and this may adversely influence the efficacy of $\mathrm{PCl}$, which relies on an oxygen-dependent photodynamic process to function effectively. PDT is less effective in spheroids owing to oxygen deprivation, as previously shown (54) using a conventional PDT photosensitiser, benzoporphyrin derivative, which like the porphyrin used here acts mainly via singlet oxygen mechanism. Interestingly, that study also found that the photoactivity of a non-porphyrin sensitiser was less sensitive to hypoxia. In another PDT study using a porphyrin photosensitiser, Alemany-Ribes et al. (2013) (55) used photophysical and singlet oxygen measurements to confirm the limitation in oxygen transport imposed by 3D cultures. The role of hypoxia in our constructs is considered further below. Development of drug-resistant clones is possible in the longer-term spheroid cultures and it has been reported that metabolic activities within 3D spheroids are reduced as cells proliferate and form aggregates. The compact structure of the spheroids could also impede resazurin (alamar blue dye) uptake (55-57).

The vital stain imaging results for $\mathrm{PCl}$ in our 3D models can be compared to previous PDT studies, as reviewed recently (31) since we also examined the effects using PDT only as a control (55). For example, Celli et al. 
(2014) (27) grew 'micronodules' of ovarian cancer on Matrigel using OVACR5 cells to study PDT effect using Verteporfin, as well as separately administered chemotherapeutics. Following PDT treatment, disaggregation of larger nodules into a number of smaller nodules were detected using E-cadherin-Alexa Fluor 488 immunostaining and 3D confocal microscopy. Such effects may also be evident in the PDT treated constructs of our current study (Figure 4B II and VI). In other PDT studies, Yang et al. (2015) (58) demonstrated synergistic PDT enhancement by applying a combination of 5- aminolevulinic acid (5-ALA) and gold nanoparticles (AuNPs) in 'spheres' developed by human breast cancer cells (MCF-7) as well as primary adipose-derived stromal cells (ASCs) on a microfluidic device. They observed a greater PDT effect in 2D cultures than the 3D model throughout all illumination periods which is also consistent with the results of our study. Gaio et al. (2016) (59) studied PDT of spheroids of Hela cells using different liposomal formulations of m-THPC, Foslip $\AA$ and Fospeg ${ }^{\circledR}$. They found limited penetration of m-THPC itself with most of the drug uptake being confined to the external cell layers of the spheroids whereas Foslip $\circledast$ and Fospeg ${ }^{\circledR}$ showed slightly higher accumulation of mTHPC within the spheroid. Another study on mTHPC showed that a different delivery vehicle based on a cyclodextrin could also improve mTHPC delivery to spheroids (60).

\subsection{Role of oxygen in PCl}

As shown in Figures 5 and S5, PDT/PCI studies carried out under hypoxia (1\%) showed that both PDT and PCI were strongly inhibited in the 3D constructs at the lower oxygen level. In contrast under hypoxia PDT and PCI were still effective for the 2D culture. We also found lower oxygenation levels in the spheroid cultures incubated under normoxia, which indicates that, the oxygen consumption levels increased as cells grew and formed spheroids (day 1 vs. day 7) (Figure 5C). Cheema et al. (2012) observed lower oxygen levels measured using a thin embedded probe in the core of a fibroblast-seeded 3D compressed collagen construct at higher seeding densities together with a localised increase in vascular endothelial growth factor (VEGF) expression (34). A recent study by VirumbralesMunoz et al. (2017) using a microfluidic 3D model has also reported development of hypoxia using the same imaging probe. However, a disadvantage of this technique is that it is difficult to determine the oxygen partial pressure accurately so these data present only qualitative comparisons (61). A sufficient supply of molecular oxygen is required for the photosensitiser TPPS $2 a$ to generate ROS upon photoactivation to induce rupture of endolysosomal membranes as required for $\mathrm{PCl}$ to take effect. The lower oxygenation levels within the larger constructs may limit the PDT effect, which initiates the ROS-induced intracellular drug redistribution and thus PCI treatment efficacy $(54,55)$. Furthermore, molecular oxygen is consumed by the photo-oxidation reactions that take place during PDT, a process often referred to as 'photochemical' consumption. Relatively low irradiances of c. $7 \mathrm{~mW} \mathrm{~cm}^{-2}$ were used in our study, which is well below levels $\left(>100 \mathrm{~mW} \mathrm{~cm}^{-2}\right)$ required to induce hyperthermia but could still induce photochemical oxygen consumption since the blue light employed is efficiently absorbed by the porphyrin. Although the effect of 
hyperthermia on $\mathrm{PCl}$ was not the focus of this study, it would be interesting in future studies to examine how hyperthermia affects the treatment outcome.

Some diminution in oxygen transport will apply to the centre of spheroids but in our study the cells are embedded within a compressed high-density collagen matrix, which is a further factor to be taken into account. The higher density of the compressed collagen constructs will reduce the rate of oxygen diffusion into the construct (62), which may be too low to counteract the rate of photochemical consumption thereby leading to a decline on oxygen levels and poorer therapeutic response. Cheema et al. (34) have shown that the rate of oxygen diffusion is a factor of ten lower in compressed collagen gels compared to uncompressed gels.

Effects of oxygenation of levels on PDT been explored previously in 2D culture with different photosensitisers $(63,64)$ and our 2D data showing partial inhibition at $1 \%$ hypoxia are in agreement with the data shown in these studies. However, in 2D culture oxygen can freely diffuse from the surrounding medium to counteract photochemical consumption effects and replenish intracellular oxygen levels, and much smaller oxygen concentrations are needed to fully abrogate PDT in 2D culture, as can be achieved using chemical methods of oxygen depletion $(65,66)$.It is also possible that $\mathrm{PCI}$ may be less sensitive to hypoxia since $\mathrm{PCl}$ can still function via partial rupture of endolysosomes, which in itself will not significantly affect viability in the absence of the cytotoxin. The lower PDT dose needed for PCI will also limit photochemical consumption of oxygen. Overall these results show however the critical importance of sufficient oxygen availability in achieving good PDT/PCl effects. Since solid tumours are often hypoxic at their cores, these results may be relevant to clinical studies.

\section{Conclusions}

This study explored the therapeutic efficacy of $\mathrm{PCl}$ in non-spheroid and spheroid compressed 3D cancer constructs using saporin as a model cytotoxin, in two human ovarian cancer cell lines, HEY and SKOV3. To corroborate the results, different types of assays were performed including imaging of the spatial response to treatment. The TPPS $2 a$ porphyrin photosensitiser used here has an analogous structure to the disulfonated tetraphenyl chlorin being used in current PCI trials with sulfonate substitution on adjacent phenyl rings (11). Furthermore neither the chlorin nor TPPS $2 a$ act as a substrate for efflux via ABCG2 transporters, which contribute to multidrug resistance (20). The presence of multidrug resistant clones, which can develop in 3D models, may be useful in further studies of $\mathrm{PCI}$ to treat cell lines that can exhibit resistance.

$\mathrm{PCl}$ was shown to be effective in both $2 \mathrm{D}$ and non-spheroid 3D cancer cultures using matching conditions for each cell line. PCl was also effective in the spheroid constructs but with reduced efficacy compared to the non-spheroid constructs for each cell line. Such a differential response has also been observed in PDT studies and may be attributable to poorer drug penetration into spheroids $(55,67,68)$. Nevertheless, our results are encouraging for the 
use of $3 \mathrm{D}$ models for $\mathrm{PCl}$ studies since the spheroid cancer constructs are a better simulation of in vivo tumours. Some differences in response however were found between the two cell lines. Better PCl efficacy was observed in the HEY spheroid constructs compared to the SKOV3 spheroid constructs for all illumination periods in contrast to the $2 \mathrm{D}$ and non-spheroid experiments. It appears therefore that HEY cells may have a greater sensitivity towards the $\mathrm{PCl}$ treatment in 3D despite their propensity to form larger aggregates compared to SKOV3 cells. The presence of lower oxygenation levels induced by spheroid development may also be a contributing factor to a lower PDT and PCI effect evoked in the spheroid constructs particularly since cells are grown within a compressed collagen hydrogel in which oxygen diffusion is slower than for a standard hydrogel. In a separate experiment we demonstrated that hypoxia can severely limit the PCl efficacy.

It will be interesting to test for differences in response using in vivo models of different cell lines to see whether the differential response observed in 3D can be replicated. HEY cells are derived from a papillary cystadenocarcinoma which is one of the most common types of ovarian cancer, and the possible use of PCl for treatment of residual microscopic disease following surgical resection of ovarian cancer should be considered by analogy with PDT, as recently reviewed by Mordon and colleagues (69). In this study, saporin was used a model agent but $\mathrm{PCl}$ is applicable to many types of bioactive agents, such as silencing RNA or biologics, and their efficacy could be rapidly screened in 3D constructs and targeting investigated (70) prior to in vivo studies. Further studies on $\mathrm{PCl}$ using nanocarriers such as dendrimers or liposomes are warranted in 3D constructs since they can better replicate the delivery restrictions imposed by the extracellular matrix. More work is required on examining the effect on PDT/PCl of including other components to the extracellular matrix such as laminin to alter the microenvironment and other cell types (e.g fibroblasts, endothelial cells and immune cells) or growth factors which affect migration and invasion (71).

\section{Acknowledgments}

We acknowledge funding from the NIHR i4i Scheme (grant number II-LA-0813-20002) and the Newton Fund (award number 334995). We would also like to thank Bala Ramesh for his support throughout the studies and Gavin Jell for the use of equipment.

\section{Disclosures}

All the authors confirm they have no conflict of interest. 


\section{References}

1. A.N. Karnezis, K.R. Cho, C.B. Gilks, C.L. Pearce, D.G. Huntsman, The disparate origins of ovarian cancers: pathogenesis and prevention strategies, Nat Rev Cancer.,17 (1) (2017), pp. 65-74.

2. K.L. Lloyd, I.A. Cree, R.S. Savage, Prediction of resistance to chemotherapy in ovarian cancer: a systematic review, BMC Cancer.,15 (2015), pp.117.

3. B. Bull-Hansen, M.B. Berstad, K. Berg, Y. Cao, E. Skarpen, A.S. Fremstedal, M.G. Rosenblum, Q. Peng, A. Weyergang, Photochemical activation of MH3-B1/rGel: a HER2-targeted treatment approach for ovarian cancer, Oncotarget., 6 (14) (2015), pp. 12436-51.

4. K. Berg, A. Weyergang, L. Prasmickaite, A. Bonsted, A. Hogset, M.T. Strand, E. Wagner, P.K. Selbo, Photochemical internalization (PCI): a technology for drug delivery, Methods Mol Biol., 635 (2010), pp.133-45.

5. A. Martinez de Pinillos Bayona, C.M. Moore, M. Loizidou, A.J. MacRobert, J.H. Woodhams, Enhancing the efficacy of cytotoxic agents for cancer therapy using photochemical internalisation, International Journal of Cancer.,138 (5) (2015), pp.1049-57.

6. A. Weyergang, M.E. Berstad, B. Bull-Hansen, C.E. Olsen, P.K. Selbo, K. Berg, Photochemical activation of drugs for the treatment of therapy-resistant cancers, Photochem Photobiol Sci.,14 (8) (2015), pp.1465-75.

7. S. Eetezadi, R. De Souza, M. Vythilingam, R. Lessa Cataldi, C. Allen, Effects of Doxorubicin Delivery Systems and Mild Hyperthermia on Tissue Penetration in 3D Cell Culture Models of Ovarian Cancer Residual Disease, Mol Pharm., 12(11) (2015), pp. 3973-85.

8. M.S. Mathews, V. Vo, E.C. Shih, G. Zamora, C.H. Sun, S.J. Madsen, H. Hirschberg, Photochemical internalization-mediated delivery of chemotherapeutic agents in human breast tumor cell lines, J Environ Pathol Toxicol Oncol., 31 (1) (2012), pp.49-59.

9. E. Yaghini, R. Dondi, K.M. Tewari, M. Loizidou, I.M. Eggleston, A.J. MacRobert, Endolysosomal targeting of a clinical chlorin photosensitiser for light-triggered delivery of nano-sized medicines, Sci Rep., 7 (1) (2017), pp.6059.

10. J.T. Wang, F. Guintini, I.M. Eggleston, S.G. Bown, A.J. MacRobert, Photochemical internalisation of a macromolecular protein toxin using a cell penetrating peptidephotosensitiser conjugate, J Control Release.,157 (2) (2012), pp.305-13.

11. A.A. Sultan, W. Jerjes, K. Berg, A. Hogset, C.A. Mosse, R. Hamoudi, Z. Hamdoon, C. Simeon, D. Camell, M. Forster, C. Hopper, Disulfonated tetraphenyl chlorin (TPCS2a)-induced photochemical internalisation of bleomycin in patients with solid malignancies: a phase 1, doseescalation, first-in-man trial. Lancet Oncol.,17 (9) (2016), pp.1217-29.

12. K. Berg, P.K. Selbo, A. Weyergang, A. Dietze, L. Prasmickaite, A. Bonsted, B.O. Engesaeter, E. Angell Petersen, T. Warloe, N. Frandsen, A. Hogset, Porphyrin-related photosensitizers for cancer imaging and therapeutic applications, J Microsc., 218 (Pt 2) (2005), pp133-47.

13. M. Lilletvedt, H.H. Tonnesen, A. Hogset, S.A. Sande, S. Kristensen, Evaluation of physicochemical properties and aggregation of the photosensitizers TPCS2a and TPPS2a in aqueous media, Pharmazie., 66 (5) (2011), pp.325-33.

14. M. Lilletvedt, H.H. Tonnesen, A. Høgset, L. Nardo, S. Kristensen, Physicochemical characterization of the photosensitizers TPCS2a and TPPS2a 1. Spectroscopic evaluation of drug -solvent interactions. Pharmazie., 65 (2010), pp.588-95.

15. T. Ohtsuki, S. Miki, S. Kobayashi, T. Haraguchi, E. Nakata, K. Hirakawa, K. Sumita, K. Watanabe, S. Okazaki, The molecular mechanism of photochemical internalization of cell penetrating peptide-cargo-photosensitizer conjugates, Sci Rep., 5 (2015), pp.18577. 
16. R. Dondi, E. Yaghini, K.M. Tewari, L. Wang, F. Giuntini, M. Loizidou, A.J. MacRobert, I.M. Eggleston, Flexible synthesis of cationic peptide-porphyrin derivatives for light-triggered drug delivery and photodynamic therapy, Org Biomol Chem.,14 (48) (2016), pp.11488-501.

17. P. Selbo, A. Weyergang, M.S. Eng, M. Bostad, G.M. Mælandsmo, A. Høgset, K. Berg, Strongly amphiphilic photosensitizers are not substrates of the cancer stem cell marker ABCG2 and provides specific and efficient light-triggered drug delivery of an EGFR-targeted cytotoxic drug, J Control Release.,159 (2) (2012), pp.197-203.

18. C.E. Olsen, A. Weyergang, V.T. Edwards, K. Berg, A. Brech, S. Weisheit, A. Høgset, P.K. Selbo, Development of resistance to photodynamic therapy (PDT) in human breast cancer cells is photosensitizer-dependent: Possible mechanisms and approaches for overcoming PDTresistance, Biochem Pharmacol.,144 (2017), pp.63-77.

19. N. Zarovni, R. Vago, T Soldà, L. Monaco, M.S. Fabbrini, Saporin as a novel suicide gene in anticancer gene therapy, Cancer Gene Therapy.,14 (2007), pp.165-73.

20. L. Polito, M. Bortolotti, D. Mercatelli, M.G. Battelli, A. Bolognesi, Saporin-S6: a useful tool in cancer therapy, Toxins (Basel)., 5 (10) (2013), pp.1698-722.

21. A. Martinez de Pinillos Bayona, J.H. Woodhams, H. Pye, R. A. Hamoudi, C.M. Moore, A.J. MacRobert. Efficacy of photochemical internalisation using disulfonated chlorin and porphyrin photosensitisers: An in vitro study in 2D and 3D prostate cancer models, cancer Lett., 393 (2017), pp.68-75.

22. D. Antoni, H. Burckel, E. Josset, G. Noel, Three-dimensional cell culture: a breakthrough in vivo, Int J Mol Sci.,16 (3) (2015), pp.5517-27.

23. J. Chen, J. Wang, Y. Zhang, D. Chen, C. Yang, C. Kai, X. Wang, F. Shi, J. Dou, Observation of ovarian cancer stem cell behavior and investigation of potential mechanisms of drug resistance in three-dimensional cell culture, J Biosci Bioeng.,118 (2) (2014), pp.214-22.

24. V. van Duinen, S.J. Trietsch, J. Joore, P. Vulto, T. Hankemeier, Microfluidic 3D cell culture: from tools to tissue models, Curr Opin Biotechnol., 35 (2015), pp.118-26.

25. D. Huh, G.A. Hamilton, D.E. Ingber, From 3D cell culture to organs-on-chips, Trends Cell Biol., 21 (12) (2011), pp.745-54.

26. C.S. Shin, B. Kwak, B. Han, K. Park, Development of an in vitro 3D tumor model to study therapeutic efficiency of an anticancer drug, Mol Pharm.,10 (6) (2013), pp.2167-75.

27. J.P. Celli, I. Rizvi, A.R. Blanden, I. Massodi, M.D. Glidden, B.W. Pogue, T. Hasan, An imagingbased platform for high-content, quantitative evaluation of therapeutic response in 3D tumour models, Sci Rep., 4 (2014), pp.3751.

28. L. Gu, D.J. Mooney, Biomaterials and emerging anticancer therapeutics: engineering the microenvironment, Nat Rev Cancer.,16 (1) (2016), pp.56-66.

29. K. Ricketts, U. Cheema, A. Nyga, A. Castoldi, C. Guazzoni, T. Magdeldin, M. Emberton, A. Gibson, G. Royle, M. Loizidou, A 3D In Vitro Cancer Model as a Platform for Nanoparticle Uptake and Imaging Investigations, Small.,10 (19) (2014), pp.3954-61.

30. A. Nyga, U. Cheema, M. Loizidou, 3D tumour models: novel in vitro approaches to cancer studies, J Cell Commun Signal., 5 (3) (2011), pp.239-48.

31. L. Mohammad-Hadi, A.J. MacRobert, M. Loizidou, E. Yaghini, Photodynamic therapy in 3D cancer models and the utilisation of nanodelivery systems, Nanoscale.,10 (4) (2018), pp.157081.

32. U. Cheema, R.A. Brown, Rapid Fabrication of Living Tissue Models by Collagen Plastic Compression: Understanding Three-Dimensional Cell Matrix Repair In Vitro, Adv Wound Care (New Rochelle)., 2 (4) (2013), pp.176-84. 
33. R. Brown, M. Wiseman, C. Chuo, U. Cheema, S. Nazhat, Ultrarapid Engineering of Biomimetic Materials and Tissues: Fabrication of Nano- and Microstructures by Plastic Compression, Advanced Functional Materials.,15 (11) (2005), pp.1762-70.

34. U. Cheema, Z. Rong, O. Kirresh, A.J. Macrobert, P. Vadgama, R.A. Brown, Oxygen diffusion through collagen scaffolds at defined densities: implications for cell survival in tissue models, $\mathrm{J}$ Tissue Eng Regen Med., 6 (1) (2012), pp.77-84.

35. C. O'Rourke, C. Hopper, A.J. MacRobert, J.B. Phillips, J.H. Woodhams, Could clinical photochemical internalisation be optimised to avoid neuronal toxicity?, Int J Pharm., 528 (1-2) (2017), pp.133-43.

36. T.J. Shaw, M.K. Senterman, K. Dawson, C.A. Crane, B.C. Vanderhyden, Characterization of intraperitoneal, orthotopic, and metastatic xenograft models of human ovarian cancer, Mol Ther.,10 (6) (2004), pp.1032-42.

37. T. Magdeldin, V. Lopez-Davila, C. Villemant, G. Cameron, R. Drake, U. Cheema, M. Loizidou, The efficacy of cetuximab in a tissue-engineered three-dimensional in vitro model of colorectal cancer, J Tissue Eng., 5 (2014), pp.2041731414544183.

38. T. Magdeldin, V. Lopez-Davila, J. Pape, G.W. Cameron, M. Emberton, M. Loizidou, U. Cheema, Engineering a vascularised 3D in vitro model of cancer progression, Sci Rep., 7 (2017), pp.44045.

39. B. Drewinko, T.L. Loo, B. Brown, A.J. Gottlieb, E.J. Freireich, Combination chemotherapy in vitro with adriamycin. Observations of additive, antagonistic, and synergistic effects when used in two-drug combinations on cultured human lymphoma cells, Cancer Biochem Biophys., 1(4) (1976), pp.187-95.

40. M.S. Mathews, J.W. Blickenstaff, E.C. Shih, G. Zamora, V. Vo, C.H. Sun, H. Hirschberg, S.J. Madsen, Photochemical internalization of bleomycin for glioma treatment, J Biomed Opt.,17 (5) (2012), pp.058001.

41. V. López-Dávila, T. Magdeldin, H. Welch, M.V. Dwek, I. Uchegbu, M. Loizidou, Efficacy of DOPE/DC-cholesterol liposomes and GCPQ micelles as AZD6244 nanocarriers in a 3D colorectal cancer in vitro model, nanomedicine.,11 (4) (2016), pp.331-44.

42. J.M. Lee, P. Mhawech-Fauceglia, N. Lee, L.C. Parsanian, Y.G. Lin, S.A. Gayther, K. Lawrenson, A three-dimensional microenvironment alters protein expression and chemosensitivity of epithelial ovarian cancer cells in vitro, Lab Invest., 2013, 93(5), pp.528-42.

43. M.M. Fretz, A. Hogset, G.A. Koning, W. Jiskoot, G. Storm, Cytosolic delivery of liposomally targeted proteins induced by photochemical internalization, Pharm Res., 24 (11) (2007), pp.2040-7.

44. K.E. Wright, E. Liniker, M. Loizidou, C. Moore, A.J. Macrobert, J.B. Phillips, Peripheral neural cell sensitivity to mTHPC-mediated photodynamic therapy in a $3 \mathrm{D}$ in vitro model, $\mathrm{Br} \mathrm{J}$ Cancer.,101 (4) (2009), pp.658-65.

45. S. Khan, J.R. Aspe, M.G Asumen, F. Almaguel, O. Odumosu, S. Acevedo-Martinez, M. De Leon, W. H. R. Langridge, N. R Wall, Extracellular, cell-permeable survivin inhibits apoptosis while promoting proliferative and metastatic potential, British Journal of Cancer.,100 (7) (2009), pp.1073-86.

46. O. Fingrut, E. Flescher, Plant stress hormones suppress the proliferation and induce apoptosis in human cancer cells, Leukemia.,16 (4) (2002), pp.608-16.

47. P.K. Selbo, M.G. Rosenblum, L.H. Cheung, W. Zhang, K. Berg, Multi-modality therapeutics with potent anti-tumor effects: photochemical internalization enhances delivery of the fusion toxin scFvMEL/rGel, PLoS One., 4 (8) (2009), e6691. 
48. C.S. Oliveira, R. Turchiello, A.J. Kowaltowski, G.L. Indig, M.S. Baptista, Major determinants of photoinduced cell death: Subcellular localization versus photosensitization efficiency, Free Radic Biol Med., 51 (4) (2011), pp.824-33.

49. D. Kessel, Y. Luo, Mitochondrial photodamage and PDT-induced apoptosis, J Photochem Photobiol B., 42 (2) (1998), pp.89-95.

50. A. Chiaviello, I. Postiglione, G. Palumbo, Targets and mechanisms of photodynamic therapy in lung cancer cells: a brief overview, Cancers (Basel)., 3 (1) (2011), pp.1014-41.

51. D. Sikriwal, P. Ghosh, J.K. Batra, Ribosome inactivating protein saporin induces apoptosis through mitochondrial cascade, independent of translation inhibition, The International Journal of Biochemistry \& Cell Biology., 40 (12) (2008), pp.2880-8.

52. T. Paullin, C. Powell, C. Menzie, R. Hill, F. Cheng, C.J. Martyniuk, S.D. Westerheide, Spheroid growth in ovarian cancer alters transcriptome responses for stress pathways and epigenetic responses, PLoS One., 12(8)(2017), :e0182930.

53. C.D. Powell, T.R. Paullin, C. Aoisa, C.J. Menzie, A. Ubaldini, S.D. Westerheide, The Heat Shock Transcription Factor HSF1 Induces Ovarian Cancer Epithelial-Mesenchymal Transition in a 3D Spheroid Growth Model, PLoS One., 11(12)(2016), :e0168389.

54. C.L. Evans, A.O. Abu-Yousif, Y.J. Park, O.J. Klein, J.P. Celli, I. Rizvi, X. Zheng, T. Hasan, Killing hypoxic cell populations in a 3D tumor model with EtNBS-PDT, PLoS One., 6 (8) (2011), e23434.

55. M. Alemany-Ribes, M. Garcia-Diaz, M. Busom, S. Nonell, C.E. Semino, Toward a 3D cellular model for studying in vitro the outcome of photodynamic treatments: accounting for the effects of tissue complexity, Tissue Eng Part A., 19(15-16) (2013), pp.1665-74.

56. A. Walzl, C. Unger, N. Kramer, D. Unterleuthner, M. Scherzer, M. Hengstschläger, D. Schwanzer-Pfeiffer, H. Dolznig, The Resazurin Reduction Assay Can Distinguish Cytotoxic from Cytostatic Compounds in Spheroid Screening Assays, SAGE., 19 (7) (2014), 1047-59.

57. K.W. Ng, D.T. Leong, D.W. Hutmacher, The challenge to measure cell proliferation in two and three dimensions, Tissue Eng.,11 (1-2) (2005), 182-91.

58. Y. Yang, X. Yang, J. Zou, C. Jia, Y. Hu, H. Du, H. Wang, Evaluation of photodynamic therapy efficiency using an in vitro three-dimensional microfluidic breast cancer tissue model, Lab Chip., 15 (3) (2015), pp.735-44.

59. E. Gaio, D. Scheglmann, E. Reddi, F. Moret, Uptake and photo-toxicity of Foscan®, Foslip® and Fospeg® in multicellular tumor spheroids, Journal of Photochemistry and Photobiology B: Biology.,161 (2016), pp.244-52.

60. I. Yakavets, I. Yankovsky, M. Millard, L. Lamy, H.P. Lassalle, A. Wiehe, V. Zorin, L. Bezdetnaya, The alteration of temoporfin distribution in multicellular tumor spheroids by beta-cyclodextrins, Int J Pharm., 529(1-2) (2017), pp. 568-75.

61. M. Virumbrales-Munoz, J.M. Ayuso, M. Olave, R. Monge, D. de Miguel, L. Martinez-Lostao, S. Le Gac, M. Doblare, I. Ochoa, L.J. Fernandez, Multiwell capillarity-based microfluidic device for the study of 3D tumour tissue-2D endothelium interactions and drug screening in co-culture models, Sci Rep., 7 (1) (2017), pp.11998.

62. U. Cheema, R.A. Brown, B. Alp, A.J. MacRobert, Spatially defined oxygen gradients and vascular endothelial growth factor expression in an engineered 3D cell model, Cell Mol Life Sci., 65(1) (2008), pp.177-86.

63. M. Price, L. Heilbrun, D. Kessel, Effects of the oxygenation level on formation of different reactive oxygen species during photodynamic therapy, Photochem Photobiol., 89 (3) (2013), pp683-6. 
64. J. Moan, S. Sommer, Oxygen dependence of the photosensitizing effect of hematoporphyrin derivative in NHIK 3025 cells, Cancer Res., 45 (4) (1985), pp1608-10.

65. L. Kunz, J.P. Connelly, J.H. Woodhams, A.J. MacRobert, Photodynamic modification of disulfonated aluminium phthalocyanine fluorescence in a macrophage cell line, Photochem Photobiol Sci., 6 (9) (2007), pp.940-8.

66. J. Woodhams, P.J. Lou, P.K. Selbo, A. Mosse, D. Oukrif, A.J. MacRobert, M. Novelli, Q. Peng, K. Berg, S.G. Bown, Intracellular re-localisation by photochemical internalisation enhances the cytotoxic effect of gelonin--quantitative studies in normal rat liver, J Control Release., 142 (3) (2010), pp.347-53.

67. J. Zhao, M. Lu, H. Lai, H. Lu, J. Lalevee, C. Barner-Kowollik, M.H. Stenzel, P. Xiao, Delivery of Amonafide from Fructose-Coated Nanodiamonds by Oxime Ligation for the Treatment of Human Breast Cancer. Biomacromolecules., 19 (2) (2018), pp.481-9.

68. J. Liu, K. Liu, L. Feng, Z. Liu, L. Xu, Comparison of nanomedicine-based chemotherapy, photodynamic therapy and photothermal therapy using reduced graphene oxide for the model system, Biomater Sci., 5 (2) (2017), pp.331-40.

69. H. Azais, G. Canlorbe, Y. Kerbage, A. Grabarz, P. Collinet, S. Mordon, Image-guided surgery in gynecologic oncology, Future Oncol., 13 (26) (2017), pp.2321-8.

70. A. Weyergang, P.K. Selbo, K. Berg, Photochemically stimulated drug delivery increases the cytotoxicity and specificity of EGF-saporin, J Control Release., 111 (1-2) (2006), pp.165-73.

71. A. Cho, V.M. Howell, E.K. Colvin, The Extracellular Matrix in Epithelial Ovarian Cancer - A Piece of a Puzzle, Front Oncol., 5 (2015), pp. 245. 